\title{
O CENTRO DE PROMOÇÃO PARA A INCLUSÃO DIGITAL, ESCOLAR E SOCIAL DE ESTUDANTES PÚBLICO-ALVO DA EDUCAÇÃO ESPECIAL
}

Ana Mayra Samuel Silva ${ }^{1}$, José Eduardo de Oliveira Evangelista Lanuti ${ }^{2}$, Ana Virginia Isiano Lima ${ }^{1}$, Fernanda Oliveira Sabino ${ }^{3}$, Denner Dias Barros ${ }^{4}$, Danielle Aparecida do Nascimento Santos ${ }^{5}$, Elisa Tomoe Moriya Schlünzen ${ }^{6}$

${ }^{1}$ Graduanda em Pedagogia na UNESP - de Presidente Prudente/SP. ${ }^{2}$ Mestrando em Educação na UNESP - de Presidente Prudente/SP. ${ }^{3}$ Graduada em Tecnologia Informática pela Faculdade de Tecnologia, campus de Mococa/SP.

${ }^{4}$ Graduando em Matemática na UNESP - de Presidente Prudente/SP. ${ }^{5}$ Mestre em Educação pela UNESP - de Presidente Prudente/SP. ${ }^{6}$ Docente da UNESP - de Presidente Prudente/SP. E-mail: ana.mayra.ss@gmail.com

\section{RESUMO}

Com o intuito de promover a inclusão digital, escolar, social e a autonomia de Estudantes Público Alvo da Educação Especial (EPAEE), foi criado em 2010 o "Centro de Promoção para Inclusão Digital, Escolar e Social" (CPIDES) na Universidade Estadual Paulista "Júlio de Mesquita Filho" campus de Presidente Prudente/SP por meio do Grupo de Pesquisa "Ambientes Potencializadores para Inclusão" (API). No CPIDES são realizados Atendimentos Educacionais Especializados (AEE), como complemento ou suplemento de atividades escolares e nestes utilizam-se recursos pedagógicos acessíveis. As atividades realizadas são direcionadas de acordo com a patologia e interesses do estudante, pois o grupo de estagiários (estudantes de graduação) atende à diversas deficiências. Para realização dos atendimentos, o API conta com recursos de Tecnologia Assistiva (TA). Os atendimentos geralmente são realizados na Sala de Recursos Multifuncionais (SRM) e no laboratório de informática do CPIDES.

Palavras-chave: Centro de Promoção para Inclusão Digital, Educacional e Social; Estudantes Público-Alvo da Educação Especial; Atendimento Educacional Especializado; Autonomia; Tecnologia Assistiva.

\section{INTRODUÇÃO E OBJETIVO}

A fim de promover a autonomia, e a inclusão digital, educacional e social de Estudantes Público Alvo da Educação Especial (EPAEE) ${ }^{1}$, em 2010, foi criado o “Centro de Promoção para Inclusão Digital, Escolar e Social" (CPIDES) na Universidade Estadual Paulista "Júlio de Mesquita Filho" campus de Presidente Prudente/SP, sob as responsabilidades da Profa Dra Elisa Tomoe Moriya Schlünzen, por meio do Grupo de Pesquisa "Ambientes Potencializadores para Inclusão" (API). Os pesquisadores do API desenvolvem estudos sobre acessibilidade, estratégias pedagógicas e metodológicas para o uso de recursos tecnológicos com o intuito de incluir pessoas com deficiências.

No CPIDES são realizados Atendimentos Educacionais Especializados (AEE) aos EPAEE, nestes utiliza-se recursos pedagógicos acessíveis e as atividades realizadas são direcionadas de

\footnotetext{
${ }^{1}$ EPAEE, segundo a Política Nacional de Educação Especial na Perspectiva da Educação Inclusiva (2007), são estudantes com deficiência (Auditiva, Física, Intelectual e Visual), transtornos globais de desenvolvimento e altas habilidades/superdotação.
} 
acordo com a patologia e interesses dos estudantes, pois o grupo de estagiários atende às diversas deficiências, a saber: autismo, paralisia cerebral, deficiência intelectual, deficiência visual, síndrome de down, entre outras. Para realização dos atendimentos, o API conta com Tecnologias Assistiva (TA $)^{2}$, que segundo Garcia e Galvão Filho (2012, p.24), "vem se tornando, cada vez mais, uma ponte para abertura de novo horizonte nos processos de aprendizagem e desenvolvimento de alunos com deficiências, incluindo até aquelas consideradas bastante severas." Os atendimentos geralmente são realizados no laboratório de informática do CPIDES e na Sala de Recursos Multifuncionais (SRM), uma vez que,

É na sala de recursos multifuncional que o aluno aprende a utilizar os recursos de TA, tendo em vista o desenvolvimento da sua autonomia. Porém, o recurso de TA não pode ser exclusivamente utilizado nessa sala, mas, encontra sentido quando o aluno utiliza essa tecnologia no contexto escolar comum, apoiando a sua escolarização. (GALVÃO FILHO e MIRANDA, 2012, p.3)

Neste trabalho produzido como forma de pesquisa bibliográfica, inicialmente tem-se por objetivo definir o conceito de autonomia relacionando-o aos EPAEE e ao AEE realizados no CPIDES, e apresentar a TA como auxiliar no processo de inclusão digital, escolar e social dos mesmos.

\section{METODOLOGIA}

Para desenvolver suas atividades de ensino, pesquisa e extensão, o grupo de pesquisa API, teve que passar pelo Comitê de Ética em Pesquisa (CEP), portanto o protocolo de aprovação é $106 / 2009$.

Antes de realizar os atendimentos junto aos sujeitos são realizadas entrevistas junto aos responsáveis pelos mesmos a fim de diagnosticar os objetivos, dificuldades, potencialidades e interesses dos estudantes. O levantamento dessas informações norteadoras é essencial para a elaboração do plano de intervenção a ser realizado com cada um dos EPAEE atendidos. As informações fornecidas pelos responsáveis nas entrevistas facilitam a pesquisa sobre os recursos de acessibilidade que podem ser utilizados com esses estudantes para a realização das atividades que serão propostas durante os $\mathrm{AEE}$, tendo em vista as principais habilidades de cada estudante,

\footnotetext{
${ }^{2}$ Segundo Garcia e Galvão Filho (2012), TA é uma área do conhecimento, de característica interdisciplinar, que engloba produtos, recursos, metodologias, estratégias, práticas e serviços que objetivam promover a funcionalidade, relacionada à atividade e participação, de pessoas com deficiência, incapacidades ou mobilidade reduzida, visando sua autonomia, independência, qualidade de vida e inclusão social. A TA é fruto da aplicação de avanços tecnológicos em áreas já estabelecidas, além de ser recurso de domínio de profissionais de várias áreas do conhecimento, que interagem para estruturar a função humana. A TA compreende a pesquisa, fabricação, uso de equipamentos, recursos ou estratégias para potencializar as habilidades funcionais dos EPAEE atendidos nas SRM, abrangendo todas as ordens do desempenho humano, desde as tarefas básicas de autocuidado até o desempenho de atividade profissional.
} 
além de suas dificuldades com relação aos conceitos matemáticos básicos, leitura, interpretação de textos e problemas, principais conteúdos desenvolvidos nos atendimentos.

Realizadas as entrevistas e a análise das mesmas é feito um levantamento bibliográfico sobre as características e especificidades que devem ser exploradas no ensino para EPAEE, de acordo com a patologia, a fim de facilitar o trabalho desenvolvido. São pesquisados também materiais relacionados aos conteúdos escolares que podem ser trabalhados com esses estudantes. Após a análise bibliográfica é realizada a escolha de recursos pedagógicos acessíveis, softwares educacionais e objetos de aprendizagem $(O A)^{3}$, a serem utilizados com os mesmos. A partir das informações levantadas, são elaborados planos de intervenção baseados no trabalho com projetos, onde são propostas atividades mediante um tema gerador para cada um dos sujeitos. De acordo com Schlünzen (2000) o desenvolvimento de projetos pode contribuir para que as informações vividas pelos EPAEE tornem-se significativas para os mesmos e possam ser transformadas em conhecimento.

A partir do plano de intervenção organizado, são utilizados OA como "Fazenda Rived", "Um Dia de Compras", "Mimocas", "Viagem Espacial” e "Festa de Aniversário", entre outros, que podem ser encontrados no Banco Internacional de Objetos Educacionais (BIOE) e no Portal do Professor. Conforme Melques et. al. (2010), o BIOE e o Portal do Professor, têm por intuito oferecer aos professores, alternativas diversificadas às aulas tradicionais, que podem contribuir no processo de ensino-aprendizagem e provocar mudanças no paradigma pedagógico. Esses recursos podem ser utilizados como aliados às atividades práticas dos temas sugeridos pelos próprios sujeitos como compra e venda de produtos, interpretação de problemas diários e sobre esporte e simulações sobre músicas e outros temas do cotidiano de interesse dos estudantes. Também são desenvolvidas atividades leituras e interpretação de textos com assuntos relacionados aos objetivos/interesses dos EPAEE. O uso de OA tem contribuído significativamente na educação e na sociedade. O foco é ser um elemento pedagógico a mais que pode potencializar o processo de ensino e aprendizagem nos AEE.

\section{RESULTADOS}

Segundo Kamii (1990, p.97-101), “autonomia significa ser governado por si próprio [...] significa levar em consideração os fatos relevantes para decidir agir da melhor forma para todos." É de suma importância garantir a todos o direito à autonomia, pois ela é a condição para a

\footnotetext{
${ }^{3}$ OA são recursos pedagógicos digitais, lúdicos e dinâmicos, que podem ser utilizados e reutilizados contribuindo para o enriquecimento dos ambientes de aprendizagem. 
liberdade do estudante, que deve ser estimulado a perguntar, criticar e criar, para que se torne apto de agir por si só.

Por meio das atividades desenvolvidas nos atendimentos, pode-se perceber claramente o avanço dos estudantes: se socializam com maior facilidade, se preocupam em realizar as tarefas propostas, interagem com o estagiário, perguntam, refletem sobre o que fizeram. Ou seja, estão desenvolvendo sua autonomia. Embora seja um processo lento, os avanços são perceptíveis com todos os estudantes atendidos.

O caso da estudante $\mathrm{J}^{4}$, por exemplo, permite comprovar que por meio do AEE realizado no CPIDES, com atividades direcionadas às suas necessidades é possível ensinar o EPAEE promovendo sua autonomia. Essa estudante, no início das atividades demonstrou-se tímida, não interagia com o estagiário e nem com os demais estudantes, realizava as tarefas sem refletir sobre o conteúdo abordado e não solicitava ajuda nem quando necessário. No final das atividades, quatro (4) meses depois, a mesma demonstrava uma melhor capacidade de se relacionar com as pessoas, realizava as atividades com maior facilidade, questionava e sugeria novos temas a serem abordados nos atendimentos. O uso da TA facilitou esse processo de construção do saber, pois facilitou sua participação e compreensão dos conteúdos, tornando-a mais autônoma.

Conforme Mantoan (1998), a autonomia, nas deficiências, é constituída de habilidades alternativas que, perante as incapacidades dos EPAEE, permitem uma adaptação conveniente às tarefas essenciais. Portanto se faz necessário desenvolver a autonomia dos EPAEE para que eles consigam realizar as tarefas essenciais do dia a dia a fim de facilitar sua vida diária. A TA pode ser um recurso que permite a compreensão a cerca dos conteúdos trabalhados e possibilita sua participação nas atividades, tornando-os independentes e autônomos.

Para Mantoan (1998) a pesquisa pedagógica deve se empenhar no sentido de promover a autonomia dos EPAEE, o que supõe o uso da TA, que é uma área do conhecimento, de característica interdisciplinar, que engloba produtos, recursos, metodologias, estratégias, práticas e serviços que objetivam promover a funcionalidade, relacionada à atividade e participação, de pessoas com deficiência, incapacidades ou mobilidade reduzida, visando sua autonomia, independência, qualidade de vida e inclusão social.

De acordo com os resultados que estão sendo obtidos no decorrer dos AEE realizados no CPIDES, pode-se concluir que a TA tem conseguido alcançar seu objetivo de ajudar aos EPAEE a desenvolver sua autonomia.

\footnotetext{
${ }^{4}$ Utilizamos a inicial do nome da estudante a fim de preservar sua identidade. 


\section{DISCUSSÃO}

De acordo com Mantoan (1998, p.4),

A construção da autonomia compreende, de um lado, a detecção, a redução ou a eliminação dos obstáculos que geram as situações de inadaptação escolar, e, do outro, o conhecimento mais aprofundado das condições de funcionamento da inteligência dessas pessoas, sem o que não se pode prover um processo interativo entre o sujeito e o meio escolar o menos deficitário possível em trocas intelectuais e interpessoais.

Os recursos e equipamentos utilizados pelos EPAEE, que frequentam o $A E E$, permite ou favorece o desempenho de tarefas, rompendo as barreiras de acesso. A ação compreende a busca de solução de problemas e, principalmente, a mudança de postura frente ao seu uso e ao papel do professor e do estudante diante desse processo.

As SRM são ambientes dotados de equipamentos pedagógicos e tecnológicos, mobiliários e materiais didáticos voltados para a oferta do AEE. A SRM é caracterizada como um ambiente para a realização do AEE para os EPAEE podendo ser temporário ou permanente. Objetivando o desenvolvimento do currículo e a participação efetiva na vida escolar dos EPAEE, devem ser utilizados os materiais e equipamentos por meio do desenvolvimento de estratégias de abordagem centradas sempre no apoio à educação realizada na classe comum.

Os EPAEE em processo de aprendizagem, que frequentam a SRM do CPIDES, estão obtendo um positivo desempenho, pois com o intermédio da TA, sentem-se mais aptos a executar atividades que antes era limitada, mas que agora se tornaram maneiras de explorar cada vez mais seus potenciais e adquirir autonomia. São viabilizadas pelas TA condições de acessibilidade que, como área de conhecimento, abrange e engloba recursos como: comunicação alternativa, acessibilidade ao computador, acessibilidade de páginas da internet, atividades de vida diárias, orientação e mobilidade, adequação postural, adaptação de veículos, órteses e próteses, entre outros.

Todas as atividades propostas e desenvolvidas no CPIDES têm por finalidade desenvolver as potencialidades dos EPAEE e para isso utilizam um ambiente Construcionista, Contextualizado e Significativo (CCS). De acordo com Schlünzen (2000, p. 82) um ambiente CCS,

É um ambiente favorável que desperta o interesse do aluno e o motiva a explorar, a pesquisar, a descrever, a refletir, a depurar as suas ideias. [...] As informações que são significativas para o aluno podem ser transformadas em conhecimento [...] O aluno consegue descobrir a relação com tudo que está aprendendo, a partir de seus interesses individuais dentro do seu contexto. 
Conforme Freire (1996, p. 58), “o respeito à autonomia e a dignidade de cada um é um imperativo ético e não um favor que podemos ou não conceder uns aos outros." Segundo ele,

O professor que desrespeita a curiosidade do educando, o seu gosto estético, a sua inquietude, a sua linguagem, mais precisamente, a sua sintaxe e a sua prosódia; o professor que ironiza o aluno, que minimiza, que manda que "ele se ponha em seu lugar" ao mais tênue sinal de sua rebeldia legítima, tanto quanto o professor que se exime do cumprimento de seu dever de propor limites à liberdade do aluno, que se furta ao dever de ensinar, de estar respeitosamente presente à experiência formadora do educando, transgride os princípios fundamentalmente éticos de nossa existência. (p.59)

Levando em consideração tais aspectos, pode-se concluir que, os estímulos gerados aos EPAEE que frequentam os atendimentos no CPIDES, partem de seus próprios interesses e dificuldades, o que tornam as atividades mais prazerosas, pois passam a despertar a atenção dos alunos atendidos, proporcionando a construção de sua autonomia e potencializando suas habilidades desenvolvidas.

\section{CONCLUSÃO}

No processo de ensino e aprendizagem de EPAEE é necessário que sejam estimulados a curiosidade e o interesse em aprender para construir o conhecimento, bem como adquirir valores necessários para sua inclusão social. Ao refletirmos sobre as atividades propostas nos AEE podemos verificar os avanços significativos em diversos aspectos dos sujeitos, principalmente relacionados à sua autonomia. Os resultados estão sendo significativos e corresponde à proposta do grupo de pesquisa, de que todos são capazes de aprender (ainda que em tempos e de formas distintas) se tiverem suas potencialidades desenvolvidas através de atividades significativas e direcionadas à sua realidade, interesses e objetivos.

\section{REFERÊNCIAS}

BRASIL: Ministério da Educação. Secretaria de Educação Especial. Política Nacional de Educação Especial na Perspectiva da Educação Inclusiva. Brasília: MEC/SEESP, 2007.

FREIRE, Paulo. Pedagogia da Autonomia: Saberes Necessários À Prática Educativa. São Paulo: Paz e Terra, 1996.

GALVÃO FILHO, Teófilo A.; MIRANDA, Therezinha G. Tecnologia Assistiva e salas de recursos: análise crítica de um modelo. In: GALVÃO FILHO, T. A. (Org.); MIRANDA, T. G. (Org.). O professor e 
a educação inclusiva: formação, práticas e lugares. Salvador: Editora da Universidade Federal da Bahia - EDUFBA, 2012, p. 247-266.

GARCIA, Jesus C. D. GALVÃO FILHO, Teófilo A. Pesquisa Nacional de Tecnologia Assistiva. São Paulo: ITS BRASIL, 2012.

KAMII, Constance. A criança e o Número: Implicações Educacionais da Teoria de Piaget para a Atuação com Escolares de 4 a 6 anos. São Paulo: Papirus, 1990.

MANTOAN, Maria T. E. Educação Escolar de Deficientes Mentais: Problemas para a pesquisa e o desenvolvimento. In: Cadernos CEDES. vol. 19. n. 46. Campinas, 1998. Disponível em: http://smec.salvador.ba.gov.br/site/documentos/espaco-virtual/espaco-educar/educacaoespecial-sala-maria-tereza-mantoan/ARTIGOS/Educacao-escolar-de-deficientes....pdf. Acessado em: 10 jul 2013.

MELQUES, Paula M. et al. Banco Internacional de Objetos Educacionais: uma ferramenta para auxiliar no processo de ensino-aprendizagem por meio do uso das Tecnologias de Informação e Comunicação (TIC). Presidente Prudente - SP, 2010. Disponível em:<http://intertemas.unitoledo.br/revista/index.php/ETIC/article/viewFile/2609/2398>.

Acessado em 04 jul. 2013.

SCHLÜNZEN, Elisa T. M. Mudanças nas práticas pedagógicas do professor: criando um ambiente construcionista, contextualizado e significativo para crianças com necessidades especiais físicas. 2000. 252 f. Tese (Doutorado em Educação). Pontifícia Universidade Católica de São Paulo, São Paulo. 